\title{
Braided Senses and Tangible Technics: Strange Encounters and Ethological Exploration at the Media Archaeology Lab
}

\author{
Christopher Loughnane \\ Auburn University
}

Abstract: This paper presents excerpts of tangible, sensual research at the University of Colorado Boulder's Media Archaeology Lab (MAL), framed within a reflection of bodily and mental experiences and a discussion of media haptics and ethological theory. It is a joining of my physico-technical experiences and the application of an ethology of media to a perceptual, sensual-semiotic analysis. My starting point is the ethological Umwelt (Uexküll 2010), an organismic subjective, perceptual world that traditionally is denoted by a dyadic structure of body plus environment connected in a data-information functional circle. I expand this definition to a non-hierarchical triadic structure of body plus environment plus technics. My intention at the MAL was to study myself through historical computing technologies, through encounters with those technologies, to use these encounters to think through ethological concepts, to reflect on how my Umwelt is formed, shaped and moulded through computing technologies from a practical, phenomenological standpoint.

In the digital age, materiality can be reactivated, because it was always a virtual condition. (Bruno 2014)

We cannot fully reckon with the gravity of surveillance capitalism and its consequences unless we can trace the scars they carve into the flesh of our daily lives. (Zuboff 2019)

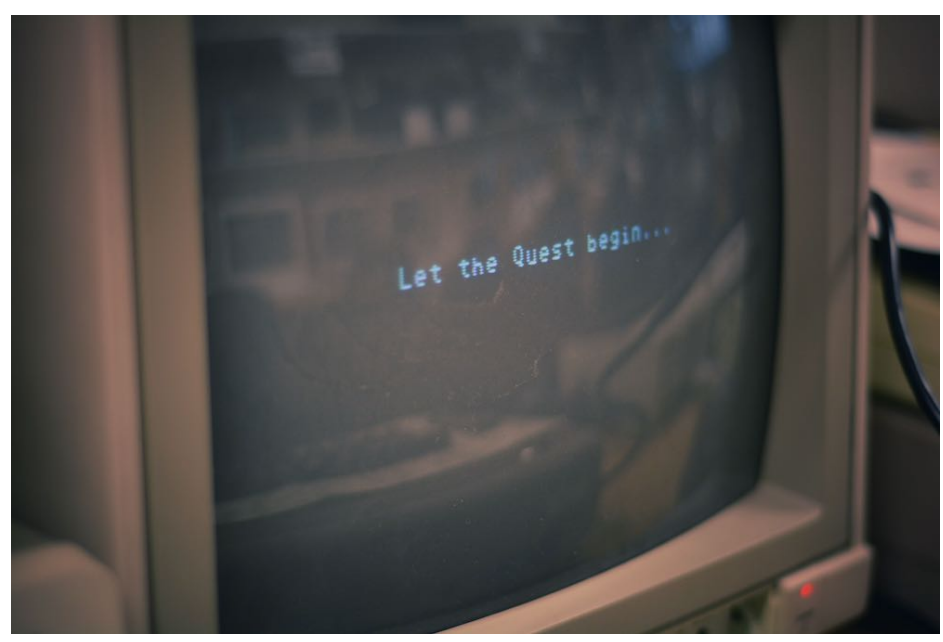

\section{Introduction}

This paper presents excerpts of tangible, sensual research at the University of Colorado- Boulder's Media Archaeology Lab (MAL), framed within a reflection of bodily and mental experiences and a discussion of media haptics and ethological theory. It is a joining of my physico-technical experiences and the application of an ethology of media to a perceptual, sensual-semiotic analysis. My starting point is the ethological Umwelt (Uexküll 2010), an organismic, subjective, perceptual world that traditionally is denoted by a dyadic structure of body plus environment connected in a datainformation functional circle. I expand this definition to a non-hierarchical triadic structure of body plus 
environment plus technics. By highlighting the triadic structure of human ethology that includes technical beingin-the-world, the effects of technologies on phenomenological existence can be shown and accounted for ethologically, existentially, and ethically.

My intention at the MAL was to study myself through historical computing technologies, through encounters with those technologies, to use these encounters to think through ethological concepts, to reflect on how my Umwelt is formed, shaped and moulded through computing technologies from a practical, phenomenological standpoint. To interrogate my perceptions as they encounter unusual technological interfaces.

In visiting the MAL I found a place where I could reimagine the bodily connections I form with technologies. This was a place where I could make my body and its technical engagements once more strange, beyond the habitude of naturalised attitudes towards technology, which veer towards invisibility through the designed steering of interfaces. Lori Emerson, founder of the MAL, makes this clear in Reading Writing Interfaces: From the Digital to the Bookbound:

The MAL is, then, a kind of thinking device that enables us to tinker and to track writing-as-tinkering in early works of digital literature; providing access to the utterly unique material specificity of these computers, their interfaces, their platforms, and their software also makes it possible to defamiliarize or make visible for critique contemporary invisible interfaces and platforms (2014:xvi).

Here was an opportunity not only to defamiliarize interfaces and platforms, but also to defamiliarize the platform of my body and its sensual-semiotic interfaces of skin and sight and sound and smell, intaking environmental and technical data and manipulating subjectivities and perceptions in this world-creation. Here I could think on the machine-body rhizome that I was forming and reforming. I could reflect on the past-present motility of the body as it presses into the future, entangles with the present, and floods through the past of memories and sensations and experiences undergone before, integrated into the skin-flesh-neuronal-environmental network of being we call a body. I decided early on in my time at the MAL that I did not want to produce only words. I wanted to capture images through a lens that was from a similar era as the MAL's holdings, a lens that was not controlled by automatic functions and so forced my body to pay more attention. The vintage Nikkor 50mm analogue lens functioned as a literalised metaphor of mediation, creating a further critical distancing from unconscious familiarised physiological action and phenomenological perception while enhancing multimodal engagement. I trained this lens, as it trained my body, on the machines and their peripherals, paying attention to the orientations of physical interface technologies such as screens, keyboards, speakers and mice. I wanted to explore my phenomenological encounters through the integration of photography and framing through secondary technology, and to recreate if possible some of my sensual experiences through the camera, by pairing this lens from the same era as much of the MAL's equipment with a digital camera body. Like most digital technology, the digital camera wants to automate most functions for you, to wrest control as its default. With a fixed manual lens you must manipulate it with your fingers (manual from manus, hand), to mechanically focus the lens along with your mind and body, to set exposure levels, to move your body back and forth without the ability to zoom in order to frame the world. Your eye is set slightly out of your body, your sight partially displaced into your hands. The tactile and the visual become intertwined through the technical nexus of camera, lens and flesh as they grasp for and envelop mediatic technologies, as they form an ethological rhizome through the triad of body, environment and technics. In this way the physicality of kinetic mobile bodies can more fully re-approach the plastic digitality of computing technics through the writing-reading virtualisation dynamic. As Gibbs and Angel (2013) argue: 
[N]ew media technologies reintroduce an animism and dynamism that re-engage the movement and gestures of the body in the scenes of writing and reading, rendering these processes explicitly performative in a way that is intimately involved in the generation of meaning.

Digital writing...call[s] forth particular kinds of body memories associated with behaviors suppressed or sublimated by typographic cultures of text. First among these is movement (reading and writing require a certain stillness), but strongly associated with it is touch, which may be linked to the capacity to reach and grasp.

What we would call an ethos of touch is evoked either through the representational aspects of the user interface or else through the movement of letters themselves.

This paper, therefore, is a mixture of media within a proscribed medium, framing my body's performative technological interactions and reality contortions in an ethos of touch and grasping, seeing and hearing, a braided (Mitchell 2005) being-in-the-world through interwoven [Verflechtung] senses and memory. Frames within frames, melding, melting and morphing. Within all media the body looms behind, above and below, a world straining to be seen through the veil of image and text. As the quote above from Zuboff indicates, it is through the personal, through our storytelling from the first-person perspective, that we can resist the modus operandi of digital devices which seek to capture, monitor and control our behaviours for profit, that scar us in the reduction of the human to networks of influence and capital. Resistance on the individual level means trying, somehow, to grasp and share the ineffable in life, that which is idiosyncratic but also, hopefully, portends to or reaches towards species commonalities without assuming a transcendental universal subject. As empathic beings we can share stories that are relatable on the level of feeling, of emotion, of sensation, of desire, of pleasure and pain. As living beings, humans are entangled in the stories of life and in the being of all existents. An ethological analysis works on the species level but can be demonstrated on the level of a particular individual. In this way, no claim to universality of experience is claimed but it shows, by example, a particular instantiation of the triadic relations between bodies, environments, and technologies. In this analysis, then, I examine the human-interface matrix from a sensuoideological, idiosyncratic perspective, exploring the ways in which physical interactions can mask, obfuscate and, alternatively, illuminate ideological operators engendered by technological manifestations.

\section{Encounters}

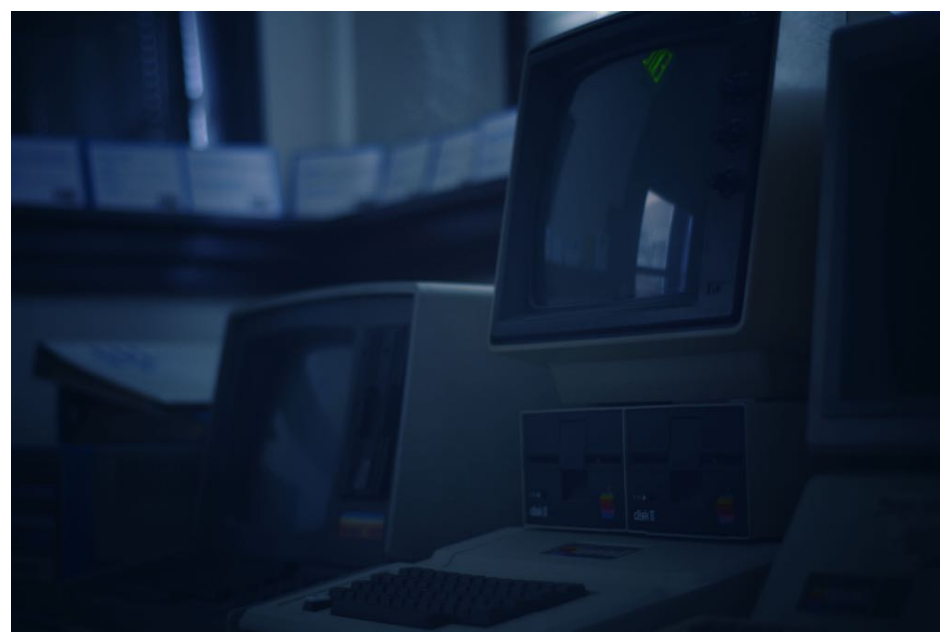


Logging on to the Apple Ile and loading bpNichol's 'First Screening' I experience this sense of anticipation and strangeness. First I must navigate a technology at once both familiar and unfamiliar. There is a screen, keyboard and disc drive, nothing unusual in itself, but where do I switch it on? How do I load the disc? How will I operate the system? I fumble with the hardware, fingers unsure. Likewise, with the software. Run commands, while partially familiar, are rarely used and certainly not as the main command interface between my body and the machine. I use them usually only when confronted with a rare diagnostic problem. Text input seems cumbersome but also surprisingly direct, as if a mediating layer between myself and the program has been removed, like the peeling of an apple skin. At the same time, the materiality of the interface is more apparent, as is the materiality of my body in its hesitancy, its lack of surety, stepping away from the confidence of the repetitive gestures - swipes, taps and pinches - that govern the use of my phone, for example. My fingers reach out tentatively, recoil, unsure. Common gestures feel unnatural because of the overwhelming presence of the body-machine connection. This is before the poems have even begun to display and the presence of another mind [artistic affect; telepresence; death of the programmer?] or of other possible meanings make themselves known.

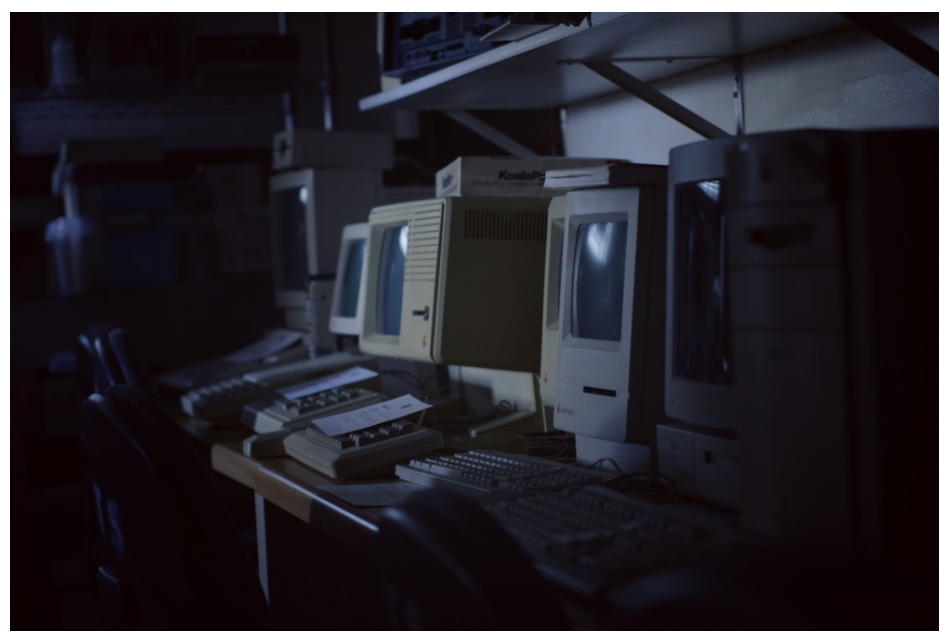

On my first visit to the MAL, I was initially overwhelmed by the physicality of the media. On reflection, this pertains in part to the massive aggregation of unfamiliar technologies. This is not a singular encounter of one new machine, but a profusion in a few basement rooms of historical computing technologies, hardware, software, peripherals, screens, discs, boxes, and most of all plastics and metals. Umwelten work on familiarity. Humans create sensual-informational heuristics of their environments to apprehend them more speedily (Berthoz 2009). Engagements with technology are likewise subsumed into the familiar of a known sensual world. Since I can remember, I have always had an abundance of sense, a heightened sensitivity to textures, sounds, lights, noises that were often too much to cope with. Crowds frightened me. Certain textures repulsed me. It was as if the normal membrane that provides the usual insulation from the outside world was too thin or missing, that the buffer that creates this sense of separation of body, brain and world, of the sense of an inside and outside, was too porous. Data would stream in, overload a flesh and neuronal system with a too-high input setting. Processing the data, turning them into rational, ordered information was difficult, at least in the moment of its reception. Percepts-as-feelings rather than thoughts would flood into the spaces of my body. The texture of a certain pillow might make my teeth ache as I lay there groaning against a perceived wrongness in the heft of it. Leaning against a wall might disrupt my inner sense of equilibrium and leave me unable to move. I would struggle to maintain balance on a shiny surface, finding it too dazzling to hold back a rushing vertigo. A standing-room-only train full of drunk football hooligans on a shopping trip with my mother when I was young was a vivid nightmare; the smell of cheap lager, sweat and stale cigarette smoke; the noise of lurid, atonal chanting; the florid, tattooed flesh; grinning faces so close to my own. My first paid-for haircut was a trauma that lacerated mind and body. I remember still the hairdresser leaning against my arm, her weight pressed against my leg, as if she were seeping into my skin, enveloping me into her folds. Silently I screamed inside for twenty minutes. But not all was bad, of course. This heightened sensitivity meant that I could often smell wonderful things others could not, or more vividly. Pleasant textures and sounds were enveloping, cocooning. Colours and forms popped and buzzed in my mind, transcendent, inspiring reams of teenage doggerel. Landscapes and seascapes were not separate from my body but swept into and through me, flooding me as I dissolved into them. 
Here in the lab textures, sights and sounds are new yet also partly remembered from a 1980s childhood. The feel and colour of certain plastics. The bittiness of screens. The clicks and clacks and beeps. Even the smell of this media, all is pervasively different and strange from the machines I am now accustomed to. From the interfaces that seek ever more to efface themselves, including in an olfactory sense. My MacBook is odourless, but perhaps it will smell in time, grow pungent in age. Yet what the lab presents is essentially an opportunity - the strangeness of the media allows a process of separation, of unweaving the lines of that technological thicket the supports our Umwelten.

The poems themselves, concrete, moving manifestations that make use of the technological frame both to display and disrupt meaning, use that enclosure to draw attention to the mind-machine interlacement. The poetry technologizes itself through its own media[tion] while at the same time forcing temporary physical passivity as it runs through its sequence. It is a form of captivity as motion forces immobility, allowing the mind to run free with associations. And of course immobility causes a particular parallel focus on the body. As Massumi[1] states, it is not passivity but motion, resonation, vibration. Bodies and machines both resonate, of course, if we listen. The hum of a monitor or drive fan. The hum of a body-mind. Resonance is mediation [body to machine] or anti-meditation. It fills mind and body. What it shares with meditation is that singular focus. Networked media allows a particular kind of inattention, of wandering focus. A non-networked artwork that makes use of the screen's/machine's materiality is an absolute physical anchor to that place and time [locally manifested network between body and machine], wherever the mind might run in its free associations. The sequence creates a syntax that the observer must not only observe but absorb and obvert. Words move on the screen, repeat, change order, make shapes, create associations through a denial of staticity and the promotion of dynamism.

All bodies resonate. Merleau-Ponty writes that 'the body is a system of motor powers that crisscross in order to produce a behavior' (2003:147-8). Bodies hum with this system of powers, whether you can hear it or not. Cells, atoms, particles are in perpetual motion. In the MAL you hear the hum and buzz and whirr of the machines. You feel the heat of their circuits, of their expended energy. But it is not the drone of a uni-type, dullard office, of a monotone Windows-pack. It is a diverse grouping of animals, collected in an artificial biome, wanting to play. They are non-networked, which enforces fidelity to their presence, and to your own. You are here, now. A particular time and space with a particular instantiation of a historical technology. But you are also not alone, in the sense of not being alone when you read a work of literature. Reader, author, brains, bodies, textual technologies; a communicable comprehension of cultural symbols as the framework of a language and a set of conventions, the symbols themselves, the manifestation of a particular media technology whether page and binding or silicon and screen. Instances of reading form a supra-synchronous entanglement of minds via sensible bodies over time and space. Technologies mediate between the body and the environment. The book itself might hold its own internal chronotope within its symbolic configuration, but the work itself both in the particular instantiation and the wider set of its manifestations exists within a larger space-time allowing transcendent communication of the body-minds that substantiate them - the traces of the neuronal networks of authors and editors activated [enacted] by the interrelationship of symbol manipulation with mind-body of reader. Software/wetware[brain]>Hardware[technology/distribution networks]>Software/wetware[brain]. Fizz, transmission, fizz. A rhizome that cuts across boundaries.

And here is bpNichol's First Screening, actively moving forward and back, up and down, traversing the screen. Building itself up, tearing itself down, creating a tower of Babel, turning inside out, back to front, deconstructing its own meanings as it piles them up semantically and spatially. Its motion, though, comes from an interior readwrite process travelling from disc to circuit to screen, a kinetic luminosity that performs a puncturing [mobile punctum] through the screen-as-archive, '[t]he tensile surface of the screen canvas' (Bruno 2014:6). 
Since digital technologies create additional environmental sensual triggers, their plasticity alters the bodyenvironment relationship, the ethological dualogue that has evolved from the biological to the cultural, which has become a triadic system of body, environment and technology. As Bruno argues, the digital screen allows [hosts, holds] simultaneity, a multiplicity of planes, of patterns, of virtual connectivity and movement on surfaces. It is a site of fluidity and transformation. The screen is not a shallow surface. Its depth, its surface tension, comes from this connectivity of relations, this space of transformations. It is an intimate space both in projection and reception, 'a form of intersubjective transfer that engages the material world and the forms of transformation that operate within its space' (9). The observer is 'enveloped' and 'absorbed' with the 'temporal effects of environmental surfaces. The sensing of a luminous surface produces such an environmental tension, for it holds us to the rhythm and passage of time in space' (87). This, she says, is related to the digital as a field of relations (93). The body is empowered by this flexibility in materiality. The surface of the flat screen becomes a threedimensional, haptic, motile space where forms move, create texture, opacity, a 'plastic materiality' (96) where the surface becomes transformed into an environment as the observer experiences, through this surface movement, a manifesting projection. The digital 'can reinvent a surface condition that is a form of materiality' (99). No matter the screen's material, this idea of surface tension creates a 'refashioning of materiality and a reinscription of textural movement on our cultural screens' (101). The screen is no longer a marginal part of a work but is a central medium. It is 'pushed to the limit of its potentiality to become the actual core and structure of the work' (101). First Screening is an affecting example of this manifest, plastic materiality that brings the surface tension of the screen to the attention of the viewer of this kinetic art as it constructs and deconstructs itself on the slight curvature of an electronic screen with its inner luminosity, unfolding both in space and time but continually adjusting the frame of its own reference. The screen of the Apple lle is a site of textural and textual intertwining, an architecture of itself as physical forms and of its digitally coded movements and manifestations:

As textural matter builds a dense plane of perceptual intersections between inside and outside, a thick, layered space of interactions between subject and object, interior and exterior, emerges in time...Not only is it constituted as a space in itself; it is a maker of space (101).

This materiality is fashioned by media as it uses the pliancy of the hybrid screen, returning a sense of temporality but also subjectivity, a spatiality of experience enabled by the material base which is nevertheless simultaneously subject to and permits its transmogrification by the dance of coded light: 'This surface-partition enables us to partake in communal forms of dwelling in the material world' (108). The digital screen hosts these simultaneous planes, these vectors of becoming, in a mediatised environment-body coupling, an Umwelt duologue that expands the territory of our dwelling in its intertwining with our physico-perceptual embrace of technology: 'The language of the screen has turned into an actual material condition of our existence. In an articulated simultaneity, virtual movements are taking place on an environment of screen surfaces' (113). Bruno calls this surface luminosity 'stains of time' (116), and if we think of the weathering of architectural forms, whether human or animal structures, time becomes visible in space, time's effects, through the laws of entropy, thermodynamics and the endless malleability of matter, inscribe this flux of being onto the surfaces that surround us. These 'layers of temporal density' (116) are overlaid on surfaces. The material world experiences this layering in the build-up of residue, but the residue of the phantasmagorical screen is in the space and shape of our perceptual experience, in the experience of the flux of time as it bubbles and warps through the body-mind becoming as it sits and watches and comprehends the multiple layers of meaning, including the cultural residue that accumulates with the creation of interwoven art forms enabled by the technical structuration of dense experience relayed by accumulating artworks embodied by media. And in the processional of concrete linguistic-semiotic markers that comprise First Screening, the viewer is captivated in a particular physical pose, sitting in front of the screen: 
The subtle, complex process of material siting exposed in the art of projection includes making room for time and history. A nonlinear sense of time and layers of temporal density emerge while traveling on the surface of media. We are engaged in observing a phantasmagoria of projection that is returning on our screens and taking place in forms of future archaeology that reinvent an archive (116).

We have here, observing the cycle of First Screening, a kinetic capture of the attention that renders an immobility of the body - to a degree. The body, like the mind, is never fully at rest, but always readjusting kinaesthetically. Artworks and media both seek to capture and immerse the world of experience, both of the psychic and the physiological which, as Merleau-Ponty states, are not experienced separately as the in-itself and for-itself but are reintegrated into existence, both directed towards a world (1994:87). Body and mind face out toward a world while at the same time always pulling that world in. This is the ethological functional circle and is, in essence, the inseparability of organism and environment. Without an environment you have no organism, and without an organism you have no environment. Media and its interfaces transpose communication beyond the ken of physical proximity of both parties. Yet despite the absence of the artist (the artist/author/auteur does not die but is continually reborn in the artist-reader communal being-in-the-work), the body of the perceiver is always present, the centre-point of perceptual experience: 'the permanence is absolute and is the ground for the relative permanence of disappearing objects, real objects. The presence and absence of external objects are only variations within a field of primordial presence, a perceptual domain over which my body exercises power' (Merleau-Ponty 1994: 92). Media does not control but it does extend and distort this primordial domain. It exercises a power to conjure perceptual objects across and through and from its dense surface. We have the power to turn from the screen, but the screen has a power to capture attention. Merleau-Ponty further writes in the Phenomenology of Perception (1994) that an external object never reveals all its sides to us without hiding the rest but that we have the power to move and choose which side to observe (90). This is only partially true of media where the screen presents a side upon a surface while withholding others. In that sense it is an amalgam of experience rather than a direct referent - we are immobilised on a singular sitting plane while we experience the motility of objects. Of course, we have the ability to move and manipulate these light-objects through inputs of peripherals such as keyboard or mouse, and this physical input remains an important distinction from the immobility of the cinema screen, whether 2D or 3D.

\footnotetext{
When the sequence ends my mind drifts away to the snow slowly falling outside, the random coherence of unique bits of matter that are non-reducible to bits per se. I rerun the sequence one, two, three more times. Each time is the same but different because the associative chains it creates are additive and at the same time unique. Layers not repetitions. Like the buildup of snow. The circuity of water as it encounters world (atmosphere, ground; eddies, runnels, dirt). Artwork, computer, person. Also a circuit. Mind, body, world. Life in medias res. Alone in a lab but not alone. The hum of machines, of thoughts. The attempt by the mind to create narrative coherence, which is arguably a byproduct of the Umwelt dynamic, data $\rightarrow$ information $\rightarrow$ world. Software here is the persistence of a perturbation, a purposive incursion into another's Umwelt. It is the intention to disrupt. To alter. To affect. To have an effect upon. And it persists until the disc itself decays.
}

Past/Present. This is not created as an historical artefact but an artistic affect. Making use of current-at-the-time technologies. How does the passage of time change representation? What does time make more clear in terms of the entanglement of software/hardware/intention/body? Here I am entangled with each further repetition.

Bruno writes: 


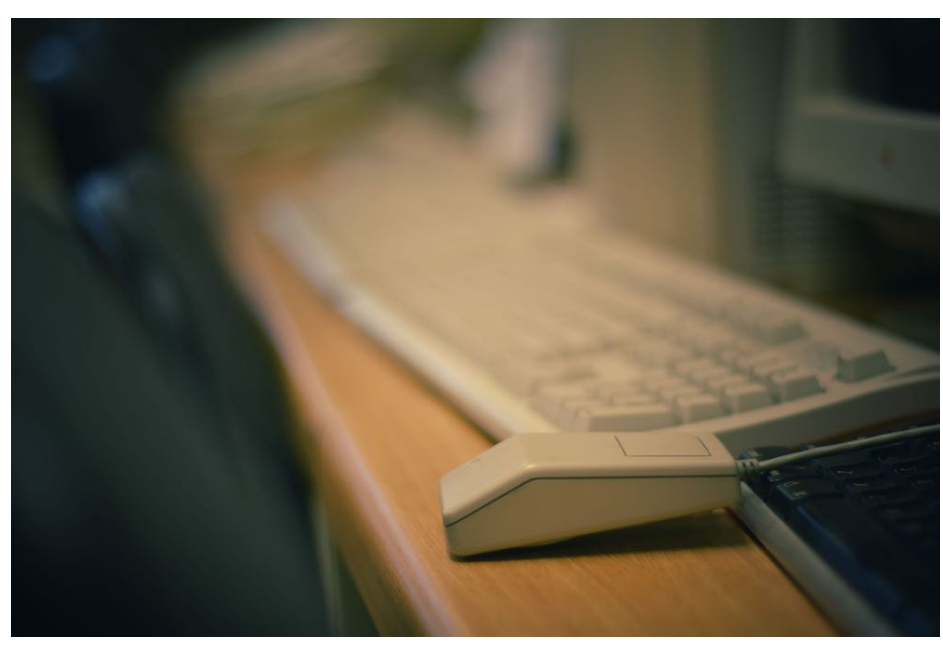

On the fabric of the screen, opacity and light, two of these critical surface data, come subtly into place to create an experiential environment that includes the landscape of interiority. In this textured, translucent fabrication, the stain of time can never be permanent (128).

The surface data includes the interiority of perception, memory, awareness of setting as the body experiences it, the pointedness of time and space but fluctuating in this mediated immersion. Fabric is an interesting term, also, originating from the Latin fabricare, meaning to construct, to build skilfully, as an artisan, a faber, would, one who works in hard materials such as stone and metal, not the textile delimitation we hold to today. Also, of a building, an appliance, a machine. Bruno talks of the fabric of the screen but we can talk, also, of the fabric of the machine, of the hardware, of the peripherals, of the totalising fabric of the skilfully constructed computing appliance. And yes, the body too. Dutch anatomist Andreas Vesalius published De humani corporis fabrica (On the Fabric of the Human Body) in 1543, bringing a new verisimilitude and accuracy to the interconnections beneath the skin, the dense weaving of flesh, bone, nerve and muscle.

The body, as Merleau-Ponty (1994) noted, is always present, whether our mental attention is focused outward or not. The body has its own awareness mechanisms, of continual feedback and control of its environment externally but also internally. Of hunger. Temperature. Tiredness. Of pleasure. Of pain. Rather than letting the body recede from view, pain brings the body into hyper-local focus: 'pain reveals itself as localized...it is constitutive of a pain-infested space' (93). Shortly before commencing the research for this project, I began to feel pain in the joints of my body, my ankles, shoulder, elbows, but especially knees and hands. My fingers in particular began to ache as if they were being crushed, sat on by an elephant. They began, too, to bend. I became intensely aware of this other kind of 'digital' existence, this continual manipulation of the world and of objects through my fingers. It is not something that, although we are aware of it, we dwell on particularly, in general life at least. But pain is a focus like no other. Human fingers are particularly dextrous, skilled, and able to conform aspects of the physical world to the will of the body. Yet despite this, it is not in manipulation, Susanne K. Langer (1974) argues, that the finger absolutely excels, though it does excel in this also, but in its evolutionary specialisation as a sense organ (257-258). Both hands can work together, can touch the same object to create a more complex single impression. At all times, the skin and its structures are mutually engaged in tactile perception, in the pressure of objects, in the feel of surfaces whether they be wet or sticky, hairy or slimy, oily or tacky. These qualities are both multimodal and often nameless. We recognise the feeling but we do not necessarily have a name for such feelings or textures. The world brims over with such complex tactility as perceived through the skin and the hands. The hand is a multimodal, epicritical organ, she argues, for perceiving the world sensually, multimodally. Sight is rich but it is of one degree only. It does not achieve the blended richness of touch. As I type this now, with my attention drawn towards these organs, I feel the textures, temperature, pressure of the surfaces that my hands rest upon and force downwards. The feel of this modern computer is entirely different to the media my hands touched in the MAL, which were less smooth, more resistant. The shape of the keys was more defined. They required greater pressure to push. The plastic was warmer than the brushed metal of this machine, which always remains cool. And each machine in the lab had a slightly different feeling, texture, temperature, stickiness or smoothness or other particularity. In fact, some of the keys were broken, which had their own effect. 

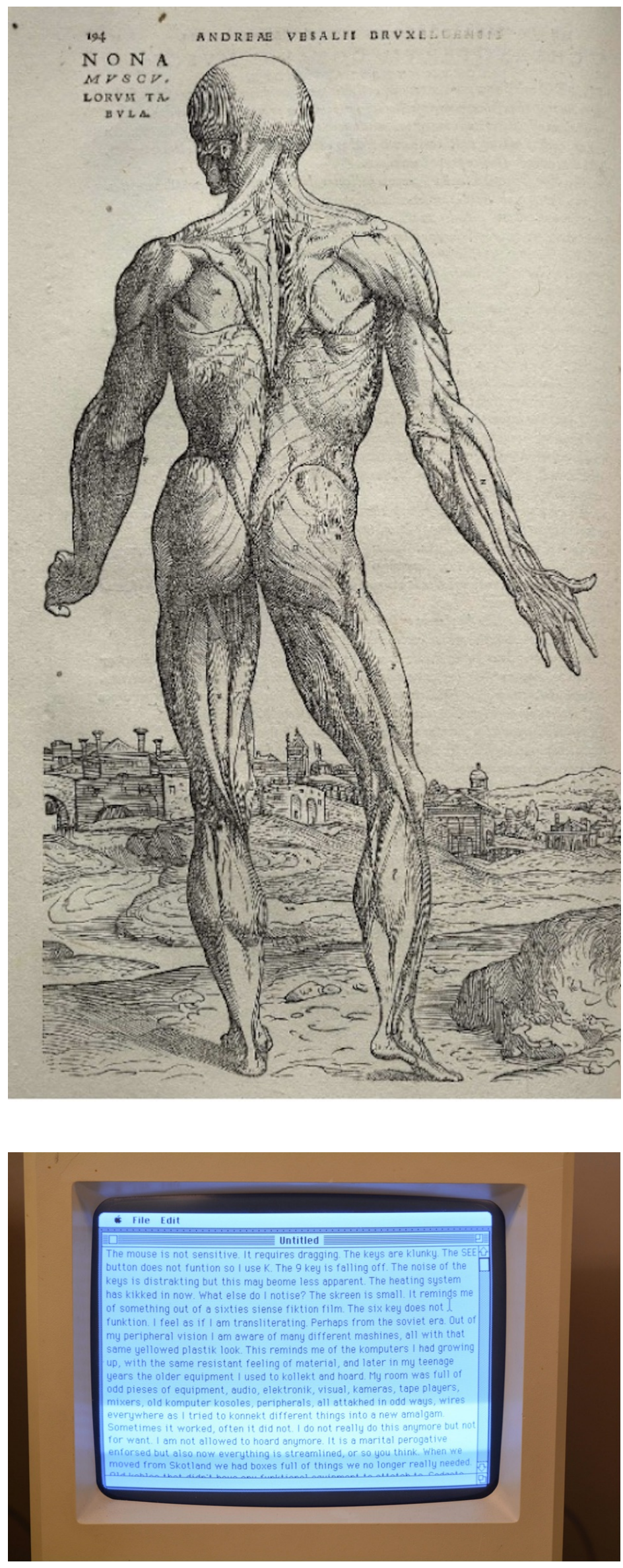

Typing is usually fairly automatic. I have incorporated the keys into my body plan. Their space and mine are intrameshed. Yet here I had to type around my meaning, use my fingertips to evade the broken promises of functioning media gone awry over time. Is time working against meaning or merely altering the possibilities of its expression? The dysfunctional key interrupts the rapture of this meaning-making, of communication. The '“productive" key' (Flusser 2011:29) is no longer productive of meaning but a hindrance to its expression. The world, according to Flusser, has disintegrated, has become intangible, and can only be made tangible once again through computation, through the gathering of particles onto surfaces, through the synthesizing of images onto the computer screen. Even with my faulty keys some meaning is being made. An image is being generated. I am transliterating it through the glitch in the hardware. But the image is still a stitch of particles, an illusion of seamlessness generated by individual points generated to create a composite whole, 'envisioned surfaces computed from particles' (33).

I used my fingers to type but they required a functioning keyboard, without which my mind was forced to adapt sounds and letters to suit my meaning. Of course, meaning is not fixed but mutative, and so is the spelling of words, which used to be much more variant until the mechanical printing press began to solidify signs and standardise our spelling. Time became clock time. Signs became concretised. Fingers, which were used not only in themselves, but to craft other tools for exploration, modification and sensing of worlds, became tools themselves, forced into spinning mills and then factories, made to repeat and count, to grow insensate and rough through chemical or mechanical abrasion, to lose their feeling for the world, a form of blindness. Finger blindness. Digital means fingers means counting numbers ten and under means human computation means digital

computation: 

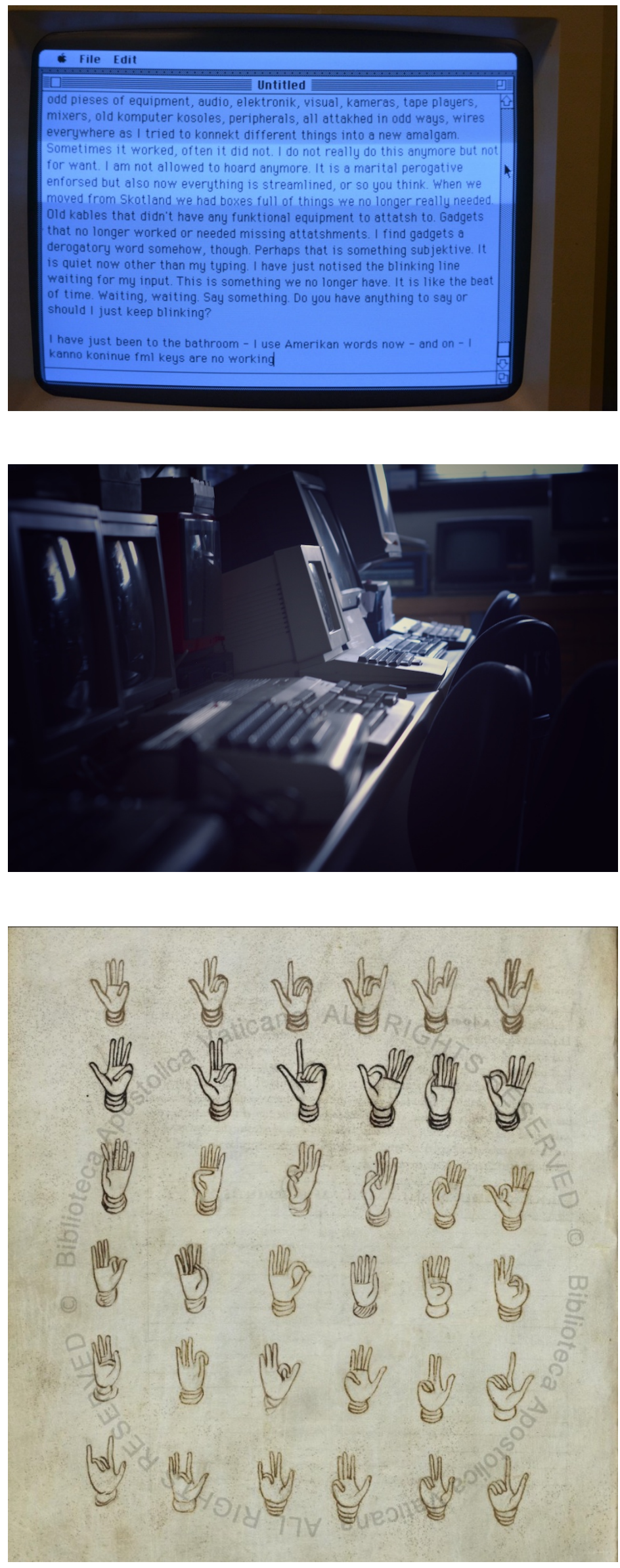

Since the fingers on one hand number five, from this is derived the number of digits on which the first counting systems were based. The ancient Greek word for this counting by fives was $\pi \varepsilon \mu \pi a ́ \zeta \varepsilon ı v$, or "fiving." Both hands together, totaling ten digits, supplied the decimal system, and ten fingers plus the two hands themselves the duodecimal system (Kapp 2018:56).

The etymology from the use of fingers for manually counting the world to digitally computing the world has a very clear lineage. The digital has always been physical. I raise a finger: one. I make a fist: zero. Yet the lineage of our finger evolution to our globally-linked media networks has been obscured. Media technologies extend the range of our Umwelten, creating synchronous and asynchronous communications possible across multimodal space. But this, too, is what the senses do. They extend and enrich our Umwelten. They allow us to perceive in a many-mirrored fashion. Without eyes or tongues or noses or ears, and indeed without fingers, our Umwelten would diminish in their congruent modalities [while potentially enriching those remaining, of course, such is the wonder of the adaptive brain].

Likewise, we must remember that our mediatic extensions are not primary but secondary organs of sense and exploration. Humans command through fingers or mouths, navigating cyberspaces from the vantage of a physically anchored body. We crawl into cyberspaces with our senses as if into rabbit holes but we are not yet fully enveloped physically by them. We do not fall into those Wonderland worlds unless by processes of dreaming while awake. The screens are, rather, looking glasses. And our fingers touch the glass as we peer inside. We are entangled by them, but not yet consumed in our entireties. This may change. Technology is becoming more addictive, more consuming. Technologies of communication are becoming more fastened to our Umwelten. This is the stated aim of developers, to stitch these technologies into the weave of our being so that we are not even aware

any longer of the physical technologies but fully immersed, engaged, addicted (Emerson 2014). 


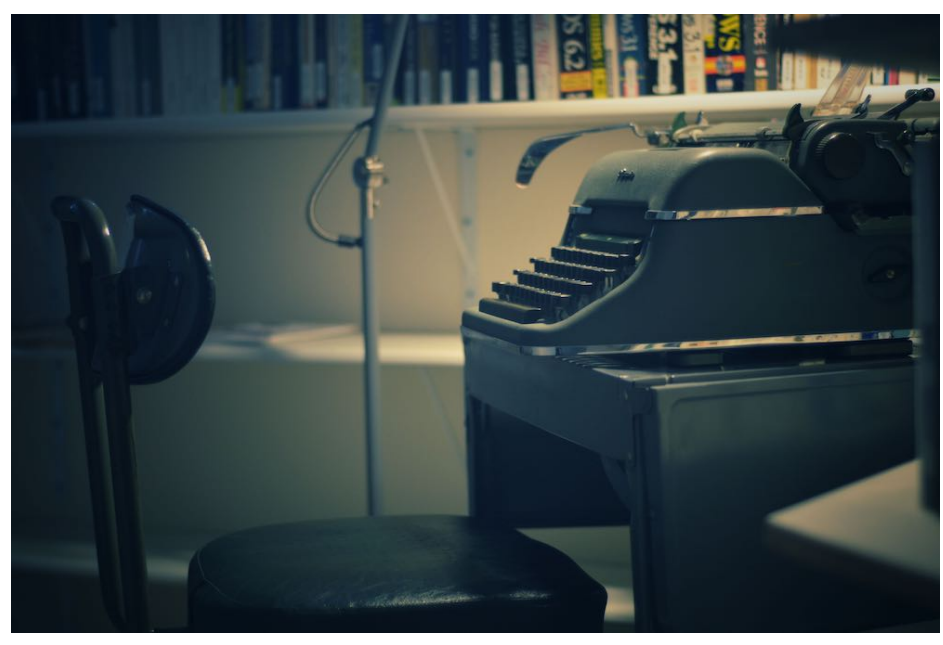

For pre-textual consciousness the image is still imbued with magical thinking (Flusser 2011). For the post-textual consciousness, post-linearity, pushing past the dominance of text, the universe dissolves into quanta, into bits of information. But these bits are not graspable directly. They must be manipulated through media technologies. Through interfaces. Via keys. For Flusser, keys are bridges between a tripartite world of atomic, human and astronomical dimensions. They work on the level of the infinitesimal, of particles, and by doing so may have effects on scales many times larger. The apparatus of the computer is black-boxed - where the mechanical action of the typewriter could previously be observed now the letters jump from the keyboard to the screen. The process has moved from the mechanical to the synthetic in the 'computing touch' (28). Yet although processes involved in this textual leaping may be black-boxed, the body is here still, endlessly touching and playing with mediatic technologies in the intermixture of body, environment and technology. It presses on. As Gibbs and Angel (2013) write:

\footnotetext{
The activity of typing conjoins gesture with signification and meaning through the medium of affect in a process that relies on the human "mimetic faculty" described by Walter Benjamin. For Benjamin, this means the capacity to translate between, or abstract immediately, from different forms of sensory experience (so that we can speak of synaesthesia, the intermingling of the senses, or of sensory experience as always taking place in the mode of "mixture" as Michel does-so too Massumi, who places more emphasis on the shifting ratios between sensory modalities)
}

What are we doing when we touch media? When we gather and manipulate particles? What does it mean to touch and be touched by a technology, a technology that is distorting of our Umwelt? What effects are being produced both bodily and in our worldview? Do we touch to wake or touch to dream? When we reach for the environment, when we mediate that environment through technology, through this tactility the world, our individual world, is not just built but grown, accreted in layers of time and space and flesh intermingling. The world we grow and fold into through touch and smell and sight and sound and taste is a thoroughly integrated fold in our organismic makeup as it involutes through the space-time fabric of existence and the inescapable entanglement of existents. Touch is primary for the flesh, for the expansion of flesh into a world. For all the talk of new haptic media, all media is and always has been haptic. Books, yes. Tablets of stone or plastic and glass and electronics, yes. Water is a medium for the body and language of the whale. What would a water-based media do to our sense of touch and connection? What would be the difference between a 'dry' and a 'wet' media? Is it a meat medium, this body? Nerve based? What about media based primarily on vibration, whether of water or air or solids? What about media experienced through vibrissae? A whisker-based media? Can we conceive of a media of horripilation, of hair and wind and temperature? Haptic feedback provides sensory susurrations, whispers of the world coming back to us through materials and motors and a multimodal mimesis of sensory conditions.

Parisi and Archer (2017) argue for the urgent need for a haptic media studies to counter the visual and aural dominance of media studies in its historical and present modes, a reorientation through the sense of touch in order to reverse the dismissal of neglected categories of media, and to create new strategies for discussing the interplay between the media and the senses. Haptic media studies are crucial in this development of an 


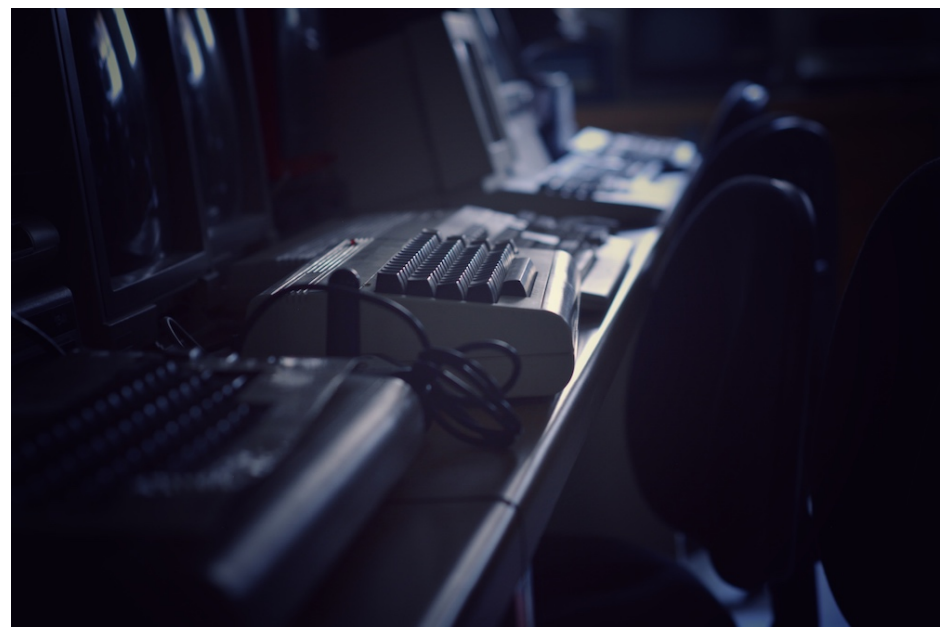

touch' (1524). ethological phenomenology of media and technics. While sight and sound have been the dominant modes of media studies not only in regard to the senses, but as defining parameters of media itself, touch and its roles in apprehending media have been comparatively ignored and under-theorized. Yet the rise of haptic media, of touchscreens, gesture-based media controllers with haptic feedback, and of wearable computing, shows the urgency for the development of a haptic media studies to demonstrate how 'media are used to encode, store, and transmit not only tactile sensations but also ideations and ideologies of

Touch, they argue, does not exist in a political or ideological vacuum but is, like all the senses, affected by its encounters by various apparatuses. In order to show the ideological nature of touch, haptic media studies must be properly placed in the genealogy of media studies in its own right and as part of the larger study of media and mediatic interactions. By treating audiovisual media as the default, the absence of research on touch-based media is increasingly apparent and problematic; even when touch is addressed it is situated in relation to the visual, as an intractable conflation where sight is still the predominant mode and touch is an additional guide or parameter. The sense of touch must not be absorbed into a more general perceptual approach to media studies, but like audio-visual sensual constructions of media, touch is neither solely a biological or phenomenological category but a constructed and continually negotiated site of meaning. By framing touch as a constructed category, it 'connects its conditions of emergence to broader shifts in the production of knowledge about the senses' and treats the senses as 'epistemic agents' both responsible for and subject to wider systems of knowledge and meaning (1527).

Situating haptic technologies in a genealogical progression with a historic lineage disrupts the utopian narratives of touch-based media and haptic interfaces which have emerged alongside the development of haptic computing technologies and their adoption in new media technologies. This emergence has been accompanied by a push to redefine haptic technologies by those who most profit from their deployment as addressing a fundamental deficiency in human touch that haptic technologies can remediate in order to bring the world more fully to hand, 'a solution to the occularcentrism of interface culture' (1533). Haptic media studies addresses, rather, the lack of attention paid to touch in media studies, creating 'an archive around touch' in order to reorient media studies away from a domineering audiovisual perspective. Parisi and Archer's conception of haptic media follows W.J.T. Mitchell's (2005) provocative argument that there is no strictly visual media, that the label 'visual media' is a prescriptive categorisation that functions as a form of ideological 'sensory hygiene.' To limit media to a single sense is to project an acceptable set of practices and habits within a preconceptualised frame of reference. It is a misleading term intended to limit media to a single sensory receptor, when in actuality media is inextricably multimodal, is always 'mixed media.' The elevation of the visual above the other senses is a predominant media fetish that reached its apotheosis in abstract modernist art, an attempt to escape into a purely visual medium that was doomed to fail because all media involves this mixture of 'sensory, perceptual and semiotic elements' (2005:260). 
Not only is there a relation of dominance and subordination, and the triggering of one sense by another, Mitchell draws attention to the phenomenon of what he calls 'braiding' where one sensory channel or semiotic function is seamlessly interwoven with another. In media terms, the mixing of sound and vision in film and television offers a straightforward example of this braiding or 'suture' of sensual elements. But sight itself, Mitchell continues, is not a singular sensorial element abstracted from other senses, nor is it something we naturally do but must learn to do, as shown by those who regain sight after blindness who must learn how to see again: 'Natural vision itself is a braiding and nesting of the optical and tactile' (263). Vision is both sight and touch. As Merleau-Ponty (1968) argues, the visible and tangible are encrusted upon one another.

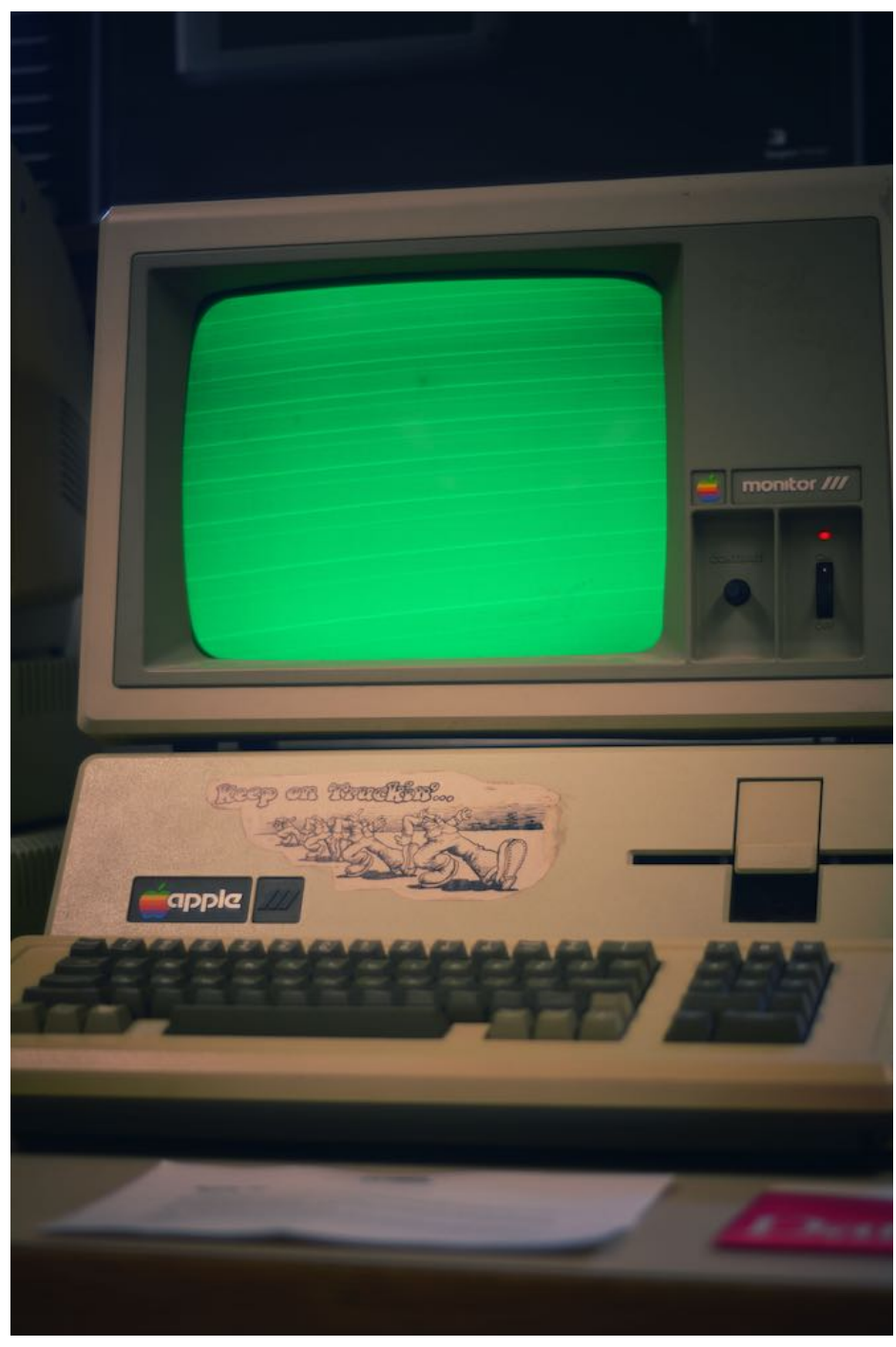

In forming Umwelten through technologies engaged by braided senses, the importance of a tactile media studies for an ethological approach to media, computing and information studies is apparent. As human senses are braided, so the oracular dominance of media offers a distorted view of sensual ratios in the bodily engagement of environment and its modelling through such sensual entanglement. An ethological analysis incorporates the tactility of media alongside other modalities of sense to offer a holistic account of how worlds are formed through mediatic engagement, of the technological absorption of media through use, of the diffusion of the body through technologies, of environmental inhabitation beyond the immediate physical environment, of environmental manipulation through information interfaces and infrastructures.

The reification of media objects into single-stream sensorial classifications further obscures the workings of semiotic operators, of the Pearcian sign exchanges essential to communication. Signs do not exist in vacuuo but in symbolic relation to one another and to the world, as repeatable coded meanings referring beyond themselves. Mitchell's aim is to work towards a more subtle media taxonomy beyond talk of 'visual' media, a taxonomy that involves empirical and phenomenological analysis (2005:262). Media is composed of two triadic structures; of the 'theoretic' primary senses of hearing, sight, touch, at the primary sensuous level of media, and of the Pearcian triadic sign-functions. The sensory-semiotic nexus, then, can involve any complex interplay between these six elements. Yet in ethological terms, these six elements identified by Mitchell sit within the higher triadic structure of body, environment and technics. The interplay of the senses and sign systems in this larger whole shows how the body and information congeal into a sensational body-world through technical manipulation of environmental situations. 


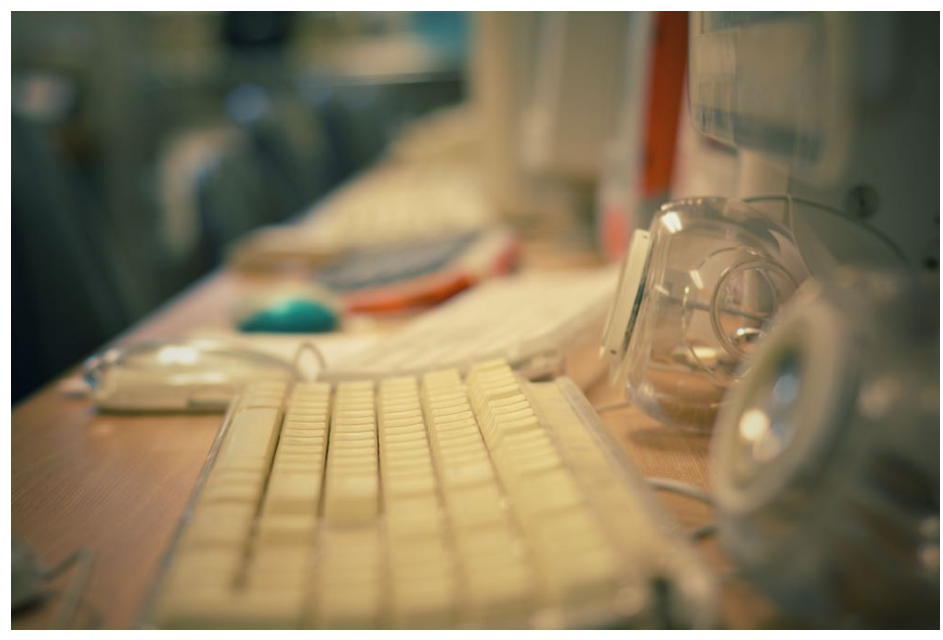

Flesh, technology and ontogenesis are merged in the rupturing of the line between life, death and decay and reel us into an un-attentional state. We exist in the flux without the mooring of conscious presence. It is a rest from the existentially exhausting state of being present. The ease of sleepwalking versus the obligations of life and duty and care. What is it to say that the world and myself as a thinking being are not held apart but are intertwined in a matrix of being and meaning? We fully encounter ourselves in the world every breathing moment, yet we are told that the I-myself, whether you call it soul or consciousness, that has its seat in the body is a perceiving, rational agent beyond that body and beyond the world to which the body belongs. We are flesh as object, yes, but the I-myself sits alone, they say, aloft above the world. From dust to dust, the body will rot, but the ecclesiastical position is that the true self will rise to heaven's domain. And even the atheistically minded amongst us still find it difficult to say that the body, this body here, frail as it is with all its aching of heart and flesh, is all we are, and all we will be, and when it is gone then so, alas, shall we. But the world itself, creator and monster, will stitch us back into its ever-folding flesh.

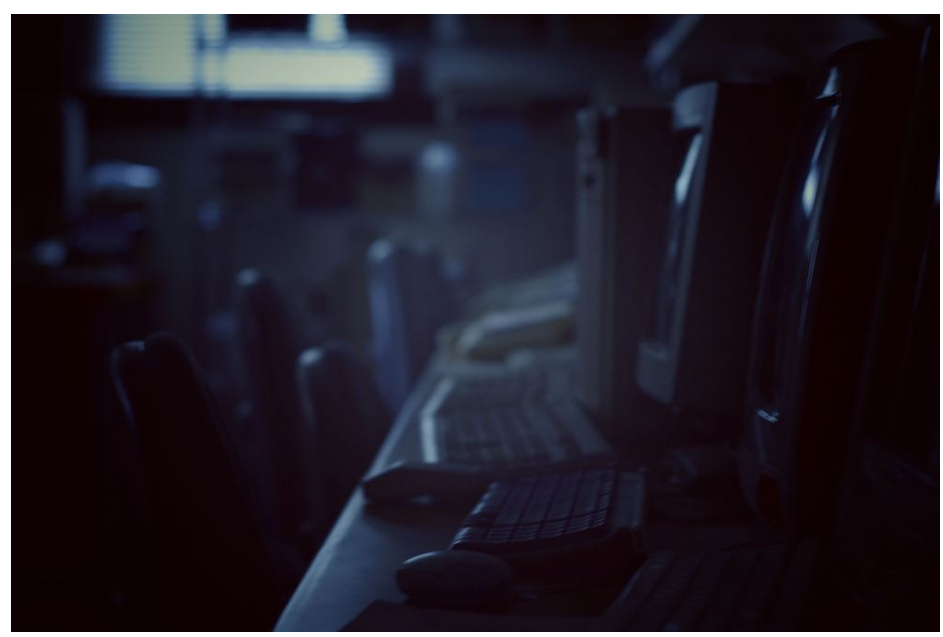

The subject-object sundering no longer holds. Outside, you see the snow whirling in the wind's currents. You look beyond the warmth of this room, protected by the glass, part of the world and yet apart from it. Is this not the same partitioning as the traditional conception of the soul, or the rational Cartesian ego? You see the snow but you do not feel it. You see the forces of the world in the buffeting of that snow, but cannot reach out your hands beyond the window. The house is a shelter but also a boundary. It draws limits on the world so that brute existence is kept at bay. But this is a metaphor only. One's world and one's perception of it are irreducibly intertwined. There is no partition. No glass. No barrier. The world is not subdivided between body and consciousness and soul and the objective this-ness of nature. The this-ness of nature would have no meaning in the derivation of its physical laws without the mind to which it makes sense, the milieu in which that knowledge is situated. Yet the instantiation of our toolmaking does exist, of the glass window and its manufacture, of the walls and their construction, of the table you type on, the cup you drink tea from, of the teabag and its construction and the growth and harvesting and drying of the tea leaves. Of the sun that beat down upon the plantations where it was grown. Of the water that sated the thirsty pickers. The technicity of this world of objects is a mutifolding cocoon. Sight and touch and technics-as-process are comingled senses. Flesh and sense are made concrete through human-oriented technological production. Through technics not only as process, but as enframing. We see [perceive] quite literally through the transparent glass of technics without realising that it is there framing our modes of perception.

Here are screens, banks of sightless seers seeing into your self. What is seen looks back. Yes the void itself but also all nodes of existence. Entrelacs. Intertwining. Vibrissae. Vibrating. What is perceived is perceiving. The sightless see through you. The handless touch through your hands as they are held. Everything held holds you in turn. You are held in the embrace of the world. Entranced, entrancing. The self as thrown into being. The illimitable self-reserve, standing reserve of the soul. The intertwining draws its power from the knotting. We are powered as much by rocks and crystals and dirt and water as electricity and sunlight.

\section{Conclusion}




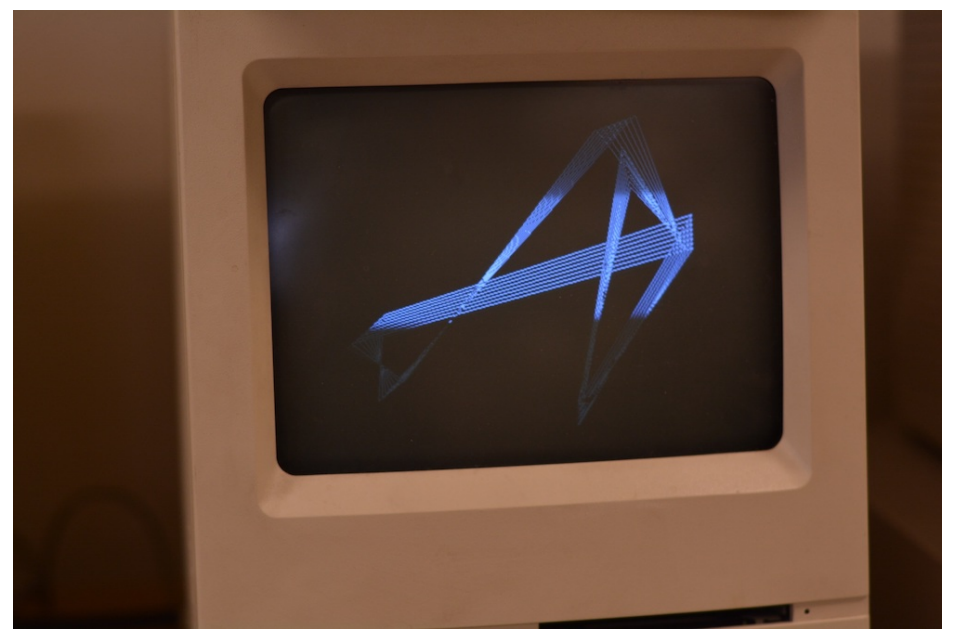

The Media Archaeology Lab is a place for ethological exploration and experimentation, bringing the triadic interplay between body, environment and technology forward into conscious awareness, into phenomenal reflection. Digital computing technologies are often more focused on the output than the process of interaction, as tools to do with rather than tools to think with. An ethological approach that uses historical technologies allows the unspoken assumptions involved in technical interactions to speak, allows the role of the body to sing where previously it was muted. Technology use is a haptic process because our ethological being-in-the-worlds we create are always funnelled through the primary medium of the body. Haptic media encounters therefore are important to developing an ethological phenomenology and a philosophy of technology viewed through an ethological lens.

The Media Archaeology Lab does more than reverse the attempt by designers to make the interface visible. By making the interface return to the body, the body [flesh] itself becomes more visible as a locus of entanglement with these technologies. Webs of being stretch both ways. The body returns to itself in the world. Loops back onto itself. Two hands touching. Worlds colliding. Technologies are incorporated into the bodily plan [Bauplan]. The body extends out into the world and the world folds back into the body. Technology mediates this functional circle, expands it and distorts it beyond the here and now. The more easily this process of technological incorporation occurs, the less critical distance we have from such carnally indoctrinating processes. The more we can force the gap open through these strange encounters that destabilise the melding of bodies with ideologically designed information systems, the more we find the space for resistance, can find room to breathe in a technologically unbalanced world.

\section{Bibliography}

@DigitaVaticana, 2018. "And that's why we say "computer" and "digital"...De computo vel loquela digitorum (On Calculating with Fingers) in De ratione temporum by Bede the Venerable. Pal. lat. 1449 (first half of 9th C.); Urb. lat. 290 (11th/13th C.); Vat. lat. 642 (12th c.); Reg. lat. 1263 (11th C.)" Twitter. April 19, 2018, 9:25am. https://twitter.com/DigitaVaticana/status/986958848274718720.

Berthoz, A., 2009. The Human Brain "Projects" upon the World, Simplifying Principles, and Rules for Perception. Neurobiology of "Umwelt": How Living Beings Perceive the World. Berlin: Springer.

Bruno, G., 2014. Surface: Matters of Aesthetics, Materiality, and Media. Chicago: University of Chicago Press.

Emerson, L., 2014. Reading Writing Interfaces: From the Digital to the Bookbound. Minneapolis: University of Minnesota Press. 


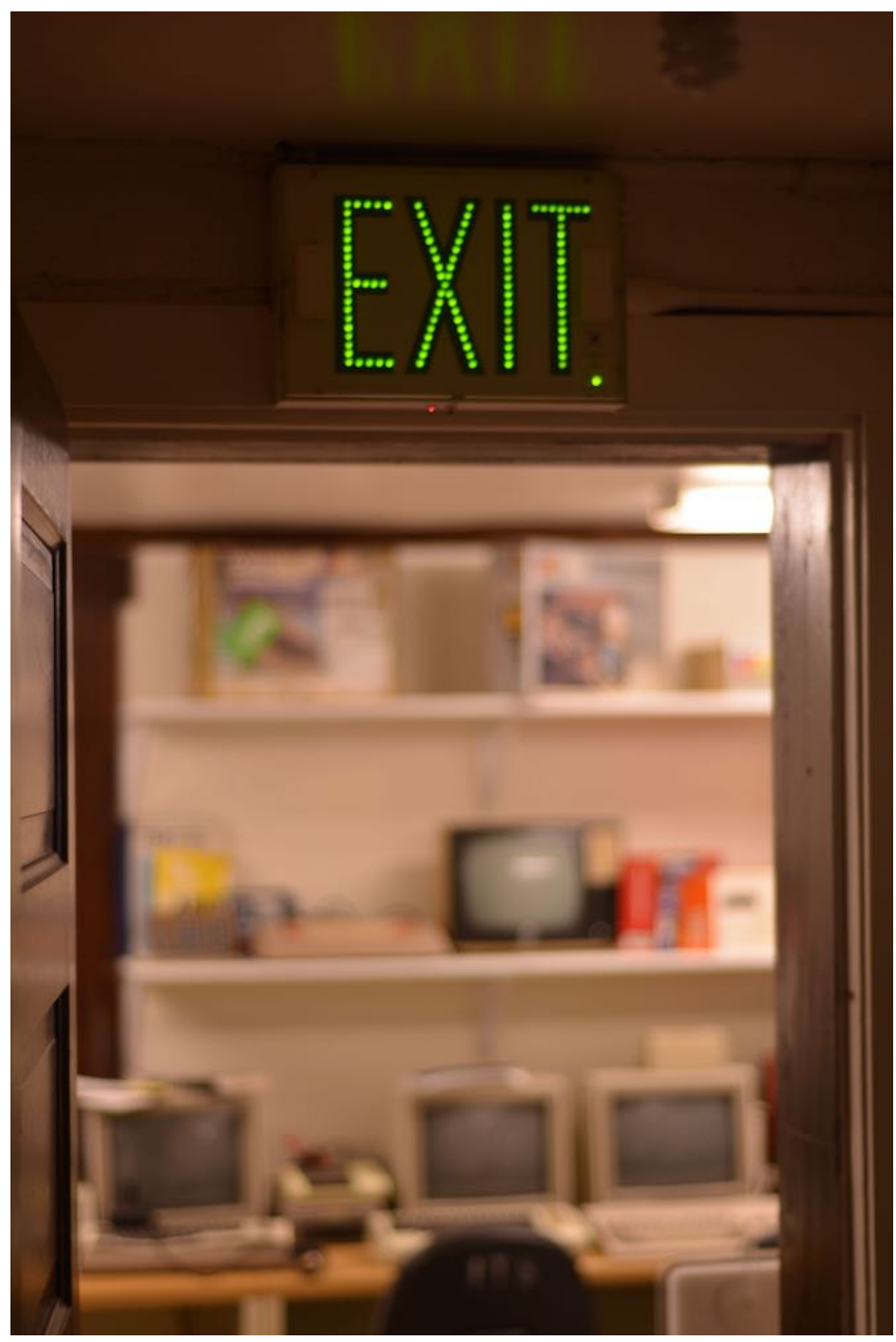

Flusser, V., 2011. Into the Universe of Technical Images. Minneapolis: University of Minnesota Press.

Kapp, E., 2018. Elements of a Philosophy of Technology: On the Evolutionary History of Culture. Minneapolis: University of Minnesota Press.

Gibbs, A., and Angel, M., 2013. "At the Time of Writing: Digital Media, Gesture, and Handwriting." Electronic Book Review, August 30, 2013.

Massumi, B., 2002. Parables for the Virtual: Movement, Affect, Sensation. Durham: Duke University Press.

Merleau-Ponty, M., 1968. The Visible and the Invisible. Evanston, Illinois: Northwestern University Press.

..., 1994. Phenomenology of Perception. Trans. Colin Smith. London: Routledge.

..., 2003. Nature: Course Notes from the College de France. Vallier, R., trans. Evanston, Illinois:

Northwestern University Press.

Mitchell, W.J.T. There Are No Visual Media. Journal of Visual Culture. 2005;4(2):257-266.

Nichol, bp., 1984. First Screening. Toronto: Underwhich Editions.

Uexküll, J., 2010. A Foray Into the Worlds of Animals and Humans. O'Neil, J.D., trans., Minneapolis: The University of Minnesota Press.

Vesalius, A., 1543. "Untitled Image." De Humani Corporis Fabrica. Accessed from https://commons.wikimedia.org/wiki/File:Vesalius_Fabrica_p194.jpg.

Zuboff, S., 2019. The Age of Surveillance Capitalism: The Fight for a Human Future at the New Frontier of Power. New York: PublicAffairs.

\section{Notes}

1. Massumi, 2002. 


\section{Cite this Essay}

Loughnane, Christopher. "Braided Senses and Tangible Technics: Strange Encounters and Ethological Exploration at the Media Archaeology Lab." Rhizomes: Cultural Studies in Emerging Knowledge, no. 37, 2021, doi:10.20415/rhiz/037.e05

RHIZOMES ISSN 1555-9998 ^ 230 East Hall Bowling Green State University Bowling Green, OH 43403

Editors: Ellen Berry and Carol Siegel. Reviews editor: Craig J. Saper. Technical editor: Helen J Burgess 